\title{
The Relationship of Structural Empowerment and Organizational Commitment Among Staff Nurses in Saudi Arabia: A Comparative Correlational Cross-sectional Study
}

\author{
Dr. Faiza Aljarameez \\ Assistant Professor, King Saud Bin Abdulziz University for Health Sciences, King Abdullah International \\ Medical Research Center, Ministry of National Guard-Health Affairs, Alhasa, Saudi Arabia
}

\begin{abstract}
Purpose: This study aimed to examine and compare the relationship between structural empowerment and organizational commitment in Saudi and non-Saudi registered nurses working in Saudi Arabia. The factors that predict organizational commitment among the two study population were also studied. Methods: Using a descriptive comparative correlational cross-sectional research design, the study was carried out in three governmental hospitals in the Eastern Province- Saudi Arabia. A convenience sample of $(\mathrm{N}=398)$ inpatient Saudi and non-Saudi nurses were included in this study. Data analysis was performed using descriptive statistics, correlation analyses, and one-way ANOVA.Findings: Statistically significant positive partial correlations were found between structural empowerment and organizational commitment. Non-Saudi nurses perceived higher levels of structural empowerment and commitment compared to Saudis. Implications for Theory, Practice, and Policy: Through the application of Kanter's (1977,1993) and Spreitzer's (1995) conceptual models, this study provided imperative and currently unavailable data that should be the foundation for future studies in the Saudi context and worldwide. Findings of this study provide evidence for the nursing authority figures to understand the relationships between empowerment and organizational commitment among nurses working in Saudi Arabia and facilitate the necessary changes to improve the current working conditions and nurses' retention.
\end{abstract}

Keywords: Nurse, Organizational commitment, Saudi Arabia, Structural empowerment, Turnover.

DOI: $10.7176 / \mathrm{JHMN} / 85-04$

Publication date: January $31^{\text {st }} 2021$

\section{INTRODUCTION}

The nursing shortage and the high turnover rate can negatively impact an organization's capacity to meet patients' demands and standards of quality of care (Church et al., 2018). An unsupportive practice environment is reported by researchers as a major contributing factor to the nurse shortage and turnover behaviors (Anderson et al., 2018; Lee et al., 2017; Rodwell et al., 2017). Globally, researches revealed that nurses who work in an unsupportive climate report uncertainty and disempowerment. When coupled with high organizational demands, these nurses develop low commitment, which in turn can contribute to nurse disengagement and withdrawal from an organization.

Employee empowerment is a multifaceted concept. In the organizational context, structural empowerment is hypothetically deemed to have an effect on job attitudes and behaviors, including organizational commitment. In her theory, Kanter $(1977,1993)$ posited that structural empowerment is achieved by having an access to six workplace power structures, including: (1) opportunity (i.e. job advancement and professional growth prospects), (2) support (i.e. guidance and feedback received from superiors, peers, and subordinates), (3) information (i.e. knowledge about organizational plans, decisions, and environmental relationships), (4) resources (i.e., human and financial resources), (5) formal power (i.e., job visibility and flexibility) and informal power (i.e., current state of affairs inside the organization). These empowerment structures provide nurses with the opportunity to actively participate in decision making processes in an organization and create more control over the work environment, which in turn, may influence the behavior and attitudes of nurses in the workplace (Kanter, 1977, 1993). Based on the common definition developed by Allen and Meyer (1993), organizational commitment, on the other hand, refers to information regarding factors that may influence an individual to leave the organization. According to Meyer et al. (1993), forms of employee commitment to an organization include: affective, continuance and normative. Affective organizational commitment is the employee's emotional attachment to, identification with, and involvement in the organization, which results in employees staying in the organization because of wanting to do so. Continuance organizational commitment refers to an individual's awareness of the relative advantages and disadvantages associated with staying or leaving an organization. Normative organizational commitment involves remaining with the organization because an individual employee feel morally obligated to stay due to fear of the potential disappointment when leaving the organization or teammates.

Worldwide, arguments exist regarding the importance of examining the phenomenon of nurse empowerment and organizational commitment to understand the current problem of nurse shortage and turnover (Aluwihare et al., 2018; Meng et al., 2015; Wong \& Laschinger, 2013). Although empowerment has several outcomes, such as 
job satisfaction and decreased work stress, organizational commitment is the major outcome necessary for organizational sustainability and development. Globally, structural empowerment has been demonstrated to have a significant measurable impact on the outcomes of nurses, patients and organizations. Structurally empowered employees are proactive, productive, satisfied, and willing to make greater contributions for the success of the organization (Gholami et al., 2019; Fragkos et al., 2020; Laschinger et al., 2009; Rodwell et al., 2017). In turn, nurses become less likely to leave the organization and level of commitment to an organization will improve. Accordingly, it can be concluded that the relationship between empowerment and organizational commitment is a significant matter of concern.

Parallel to the global research, is the national view of nursing in the Saudi work environment where disempowerment, emotional exhaustion, dissatisfaction with payment, workload, and leadership support, and lack of educational and promotion opportunities are cited as a rationale for a decline in commitment and an increase of intent to leave either the organization or the profession (Abumayyaleh et al., 2016; Al-Yami et al., 2018; Asiri et al., 2016). Asiri et al (2016) emphasized empowerment of nurses working in the Saudi health care settings offers opportunities for more active, autonomous and responsible involvement in operational decision making as well as personal learning and development. Consequently, nurses can develop a sense of self-worth, autonomy, role meaningfulness, engagement, morale and job satisfaction and organizational commitment (Alghamdi et al., 2016; Asiri et al., 2016). As a result, the quality of nursing working conditions and staff nurses' retention rates may be improved (Almutairi, 2015; Asiri et al., 2016; Salem et al., 2016). When examining the variations, nationality was regarded as a confounding factor affecting nurses' perceptions on empowerment and organizational commitment. Such differences have been highlighted by previous studies, such as those found between nurses from Malaysia and England (Ahmad \& Oranye, 2010), Arab and non-Arab nationalities in Saudi hospital settings (Asiri et al., 2016), and American and Filipino nurses working in USA (Vacharakiat, 2008). Despite the vast amount of international research, in Saudi Arabia, there remains a lack of explanation of the factors that define work empowerment and contribute to organizational commitment in the workplace. Those Saudi research studies were mainly conducted to assess certain dimensions of empowerment, such as nurses' leadership, managerial support, obstacles of competence and performance of nurses (Abumayyaleh et al., 2016). The review revealed a gap in this area of research that should be thoroughly investigated to build an understanding about nursing working conditions and nurses' perceptions of empowerment and organizational commitment. Due to differences in the cultural context and in the healthcare system in Saudi Arabia, the perspectives and evaluations of empowerment and organizational commitment as well as recommended interventional strategies may differ from those found in the Western countries (Almalki et al., 2012). Therefore, it was crucial to investigate the phenomenon in the Saudi context to build an understanding about the existing structural working conditions and factors that staff nurses perceive as disempowering or non-motivating to stay committed to an organization. Thus, the primary purpose of this study was to examine and compare the relationships among nurses' perceptions of structural empowerment and organizational commitment in two main groups: Saudi and non-Saudi registered staff nurses working in inpatient units in Saudi Arabia. The study also aimed to investigate what factors predict organizational commitment among the two study populations.

\section{METHODS}

Study Design

The study employed a descriptive comparative correlational cross-sectional research design

\section{Setting}

The study took a place in three governmental hospital settings in Eastern Province, the largest province of Saudi Arabia by area, including: King Fahad Specialist Hospital-Dammam (KFSH-D), Qatif Central Hospital, and Dammam Medical Complex. Ethical approval for the study was obtained from the Saudi Ministry of Health and the Ethics Committees of the three participating hospitals (IRB Log Number:EXT0350). Approval to use copyrighted materials (CEWQ-II and TCM) was obtained from the original authors. Data collection was planned over a three-month period between April to June 2019. Completion and return of questionnaire implied a consent to participate in the study. Nurses were asked to place the completed anonymous questionnaire in the envelope and return it to a secured box located in each participating inpatient unit of the three hospital settings. Every week over the three-month period, the primary investigator made a follow-up visit to the three participating hospitals to track the response rate and collect the completed questionnaires.

\section{Inclusion and Exclusion Criteria}

The study included a convenience sample of full-time Saudi and non-Saudi nurses employed at the three targeted hospital settings who work at bedside with direct interaction with patients and have spent at least three months in current working unit. The exclusion criteria included: part-time nurses, nurses who spent less than three months in current unit, nurse students, non-bedside and nurse administrators such as nurse managers, nurse educators, and 
assistant nurse managers.

\section{Variables}

The study included one main independent predictor variable (i.e., structural empowerment) and three forms of dependent variable (i.e., affective, continuance, and normative organizational commitment). Structural empowerment is theoretically defined based on Kanter $(1977,1993)$ theory as an organization's ability to provide access to lines of power that originate from particular organizational attributes: opportunity, support, information, resources, formal and informal power in the work environment. The outcome variable, organizational commitment, is theoretically conceptualized based on the common definition developed by Allen and Meyer (1993) as information regarding factors that may influence an individual to leave the organization. The Three-Component Commitment Model (TCM) (Meyer et al., 1993). was used to operationally define and measure three forms of employee commitment to an organization: desire-based (affective), cost-based (continuance), and obligation-based (normative).

\section{Data Collection}

The theoretical framework of this study was based on Kanter's $(1977,1993)$ Theory of Structural Empowerment. Structural empowerment was measured using the Conditions of Work Effectiveness Questionnaire-II (CWEQ-II) which was developed by Laschinger et al (2001) to measure the six components of Kanter's theory. The CWEQII consists of 19 self-reported items across six subscales as a measure of the respondent's perception of structural empowerment rated on a 5-point Likert scale ranges from low perceptions indicated by $(1=$ none $)$ to high perceptions of access to empowerment structure indicated by $(5=\mathrm{a}$ lot $)$. Four subscales reflect the dimensions of structural empowerment: opportunity, support, information and resources and the two other subscales: Job Activities Scale (JAS) is to measure formal power and Organizational Relationships Scale (ORS) is to measure informal power. With the exception of the informal power subscale, each subscale consists of three items. For the present study, the overall Cronbach's alpha reliability coefficient for the 19-structural empowerment (CWEQ-II) items of the six subscales was .95. Summing the means of six subscales yields a composite structural empowerment score ranging between 6 and 30; with higher scores representing stronger perceptions of structural empowerment. Scores ranging from 6 to 13 are described as low levels of empowerment, 14 to 22 as moderate levels of empowerment, and 23 to 30 as high levels of empowerment (Laschinger, 2012).

Organizational commitment was measured using the Three-Component Commitment Model (TCM). TCM by Meyer et al., 1993). The TCM model by Meyer et al. (1993) was designed to operationally measure three forms of employee commitment to an organization: desire-based (affective), cost-based (continuance), and obligationbased (normative). Each subscale is measured by a six item (18 total items), 7-point Likert scale with $(1=$ strongly disagree) and $(7=$ strongly agree $)$. Without producing a composite scale-level score, nurses' perception of organizational commitment was measured by assessing the individual mean for each subscale, yielding a subscale mean score ranging between 1-7, with higher mean scores representing stronger perceptions of organizational commitment. For the present study, the overall Cronbach's alpha reliability coefficient for the 18 items of the three subscales comprising the TCM scale was .81, with (.76) for affective commitment, (.76) for continuance commitment, and (.72) for normative commitment.

To ascertain consensual validity and ensure that the wording of statements in the questionnaire met the objective of the study and the instructions were clear with no ambiguous, inaccurate, incomprehensive, or culturally inappropriate terms or questions, the skills of three bilingual nursing experts who spoke Arabic and English were used to review the bilingual version of the questionnaire. The expert panel's feedback was used to reword any items as indicated. The changes were made on 12 items of the Arabic version. The changes mainly included rewording of the Arabic statements that appeared redundant or misunderstood to read in the same fashion as the English version. The necessary modifications were made prior to finalization of the instruments for the main study.

\section{Sample Size}

A total of 450 questionnaires were distributed in the three targeted hospital settings. In response, a total of 406 were returned, yielding a response rate of $90.2 \%$. Following data cleaning, responses with more than $10 \%$ missing data were excluded $(n=8)$. Thus, an overall $(N=398)$ questionnaires that provided a final adequate sample size for coding and statistical analyses.

\section{Statistical Analysis}

Using SPSS (v.22), descriptive statistics were computed for the demographic data. Partial Pearson's r was used to examine the correlation among the research variables while controlling for the confounding factors. One-way ANCOVA, a combination of ANOVA and regression analyses to compare the means of the two independent study groups (Saudis vs. non-Saudis). One-way ANOVA analyses was used to predict the significant and insignificant 
predictors of organizational commitment. To control bias and evaluate which demographic or professional characteristic variables might have presented a confounding effect when comparing Saudi versus non-Saudi nurses on the key variables of structural empowerment and organizational commitment, a threshold of three or more Partial-Eta Squared $\left(\eta p^{2}\right)$ values $>.10$ and Chi-Square Test for Equality of Proportions were used to identify and confirm potential confounders (i.e., covariate variables) in need of further exploration.

\section{FINDINGS}

Details of sample demographics descriptive analyses are presented in Table 1. Through Bonferroni post hoc test adjustment for multiple comparisons, (1) nationality, (2) hospital setting, (3) work unit and (4) length of work shift were regarded as confounding factors, and thus controlled during all statistical analyses, leading to significant variations of nurses' perceptions toward empowerment and organizational commitment.

Table 1: Descriptive Analysis of Sample Demographic Characteristics $(N=398)$

\begin{tabular}{|c|c|c|}
\hline $\begin{array}{l}\text { Variable and } \\
\text { Category }\end{array}$ & Frequency $(n)$ & $\begin{array}{l}\text { Percentage } \\
\quad(\%)\end{array}$ \\
\hline \multicolumn{3}{|l|}{ Gender } \\
\hline Male & 49 & 12.3 \\
\hline Female & 346 & 86.9 \\
\hline \multicolumn{3}{|l|}{ Age } \\
\hline $20-29$ & 114 & 28.6 \\
\hline $30-39$ & 188 & 74.2 \\
\hline $40-49$ & 38 & 9.5 \\
\hline "50 and more" & 4 & 1.0 \\
\hline \multicolumn{3}{|l|}{ Nationality } \\
\hline Saudi & 221 & 55.5 \\
\hline Non-Saudi & 173 & 43.5 \\
\hline \multicolumn{3}{|l|}{ Ethnicity } \\
\hline Arab & 222 & 55.8 \\
\hline Asian & 87 & 20.6 \\
\hline Indian & 82 & 20.6 \\
\hline Other & 1 & .3 \\
\hline \multicolumn{3}{|l|}{ Educational Level } \\
\hline Diploma & 166 & 41.7 \\
\hline Associate Degree & 5 & 1.3 \\
\hline Bachelor & 202 & 50.8 \\
\hline Master & 5 & 1.3 \\
\hline Doctoral & 1 & .3 \\
\hline Other & 2 & .5 \\
\hline \multicolumn{3}{|l|}{ Monthly Salary Range } \\
\hline SR $1,500-5,000(\$ 400-\$ 1,333$ US $)$ & 42 & 10.6 \\
\hline SR 5,001-10,000 (\$1,334 - \$2,666 US) & 214 & 53.8 \\
\hline SR $10,001-15,000(\$ 2,667-\$ 4,000$ US $)$ & 121 & 30.4 \\
\hline$>$ SR $15,001(>\$ 4,001 \mathrm{US})$ & 7 & 1.8 \\
\hline \multicolumn{3}{|l|}{ Length of Nursing Experience } \\
\hline 3-6 months & 11 & 2.8 \\
\hline 7-12 months & 23 & 5.8 \\
\hline $1-2$ years & 11 & 2.8 \\
\hline $3-5$ years & 85 & 21.4 \\
\hline $6-10$ years & 164 & 41.2 \\
\hline$>10$ years & 98 & 24.6 \\
\hline
\end{tabular}


Work Unit

Medical

Surgical

Critical Care ICU

Pediatrics

Trauma

Burn Unit

Other

Time Spent in Current Unit

3-6 months

7-12 months

Length of Regularly Shift

8 Hours

12 Hours

At a significance level $(p<.001)$, most of the findings indicated statistically significant very weak to moderate positive partial correlation between the variables of interest (Table 2). Total structural empowerment demonstrated the strongest statistically significant positive partial correlation with affective commitment $(r=.47, p<.001)$ and the weakest but insignificant partial correlation with continuance commitment.

Table 2 Partial Correlation Pairs Matrix Between the Research Variables

\begin{tabular}{|c|c|c|c|c|c|c|c|c|c|c|c|c|c|c|}
\hline $\begin{array}{l}\text { Variables } \\
\text { and } \\
\text { Subscales }\end{array}$ & Opp & Res & Info & Sup & FP & IP & Total & PEM & PEC & PED & PEI & $\mathrm{AOC}$ & $\mathrm{COC}$ & $\mathrm{NOC}$ \\
\hline Opp & 1.00 & & & & & & & & & & & & & \\
\hline Res & .45 & 1.00 & & & & & & & & & & & & \\
\hline Infor & .47 & .58 & 1.00 & & & & & & & & & & & \\
\hline Sup & .58 & .52 & .62 & 1.00 & & & & & & & & & & \\
\hline $\mathrm{FP}$ & .48 & .63 & .59 & .53 & 1.00 & & & & & & & & & \\
\hline IP & .49 & .54 & .57 & .60 & .58 & 1.00 & & & & & & & & \\
\hline Total & .72 & .77 & .82 & .79 & .82 & .79 & 1.00 & & & & & & & \\
\hline $\mathrm{AOC}$ & .29 & .36 & .42 & .33 & .41 & .39 & .47 & .30 & .19 & .18 & .31 & 1.00 & & \\
\hline $\mathrm{COC}$ & $.07 *$ & $.04 *$ & $.05^{*}$ & .10 & $.06^{*}$ & .17 & $.09 *$ & .11 & .16 & .16 & .23 & .07 & 1.00 & \\
\hline NOC & .27 & .33 & .33 & .36 & .29 & .34 & .41 & .28 & .19 & .24 & .33 & .43 & .39 & 1.00 \\
\hline
\end{tabular}

Note. All partial correlation coefficient correlations $(r)$ presented were statistically significant with $p<.05$. Correlations denoted with ${ }^{*}$ were statistically insignificant at $p \leq .05$. Opp $=$ Opportunity. Res $=$ Resources. Info $=$ Information. Sup $=$ Support. FP $=$ formal power. IP $=$ informal power. Total $=$ Total Structural Empowerment. Organizational Commitment: $\mathrm{AOC}=$ affective. $\mathrm{COC}=$ continuance. $\mathrm{NOC}=$ normative.

Overall, based on nationality, the results of a one-way ANOVA revealed a statistically significant mean difference between Saudi and non-Saudi nurses in total structural empowerment $(F(1,392)=152.40, p<.001)$. However, the effect size of these differences was statistically significantly small $\left(\eta \mathrm{p}^{2}=.03-.28\right)$ (Table 3$)$. Overall, the non-Saudi group scored statistically significantly higher on total structural empowerment $(M=22.08, S E=.46)$ than Saudis $(M=18.72, S E=.52, p<.001)$. For organizational commitment, the non-Saudi group also perceived higher but statistically insignificant levels on affective and normative commitment than the Saudi group. Of exception, Saudi nurses demonstrated better but statistically insignificant level of continuance commitment $(M=$ $4.72, S E=.15)$ as compared to non-Saudi nurses $(M=4.41, S E=.14, p=.14)$ (Table 4). 
Table 3: Mean Difference and One-way ANOVA Comparing Nationality Groups on Research Variables

\begin{tabular}{|c|c|c|c|c|c|c|c|c|}
\hline $\begin{array}{l}\text { Variables and } \\
\text { Subscales }\end{array}$ & $\begin{array}{c}\text { Saudi } \\
(n=221)\end{array}$ & $\begin{array}{c}\text { Non-Saudi } \\
(n=173)\end{array}$ & $\begin{array}{c}\text { Mean } \\
\text { Difference }\end{array}$ & \multicolumn{2}{|l|}{$d f$} & \multirow[t]{2}{*}{$F$} & \multirow[t]{2}{*}{$p$} & \multirow[t]{2}{*}{$\eta p^{2}$} \\
\hline & $M(S D)$ & $M(S D)$ & $M(S D)$ & & & & & \\
\hline & & & & Between Group & 1 & & & \\
\hline $\begin{array}{l}\text { Total Structural } \\
\text { Empowerment }\end{array}$ & $17.19(4.63)$ & $22.65(3.97)$ & $19.52(5.16)$ & Within Group & 392 & 152.40 & .000 & .28 \\
\hline & & & & Total & 393 & & & \\
\hline $\begin{array}{l}\text { Affective } \\
\text { Commitment }\end{array}$ & $4.13(1.22)$ & $4.74(1.11)$ & $4.39(1.21)$ & Between Group & 1 & 26.70 & .000 & .06 \\
\hline Continuance & $4.82(1.20)$ & $4.42(1.09)$ & $4.64(1.18)$ & Within Group & 392 & 11.60 & .001 & .03 \\
\hline $\begin{array}{l}\text { Normative } \\
\text { Commitment }\end{array}$ & $4.25(1.36)$ & $4.66(.88)$ & $4.42(1.18)$ & Total & 393 & 11.89 & .001 & .03 \\
\hline
\end{tabular}

Note. $\mathrm{df}=$ Degree of Freedom. $\eta \mathrm{p}^{2}=$ Partial-Eta Squared

Table 4 Pairwise Comparisons Between Saudi and Non-Saudi Nurses: Covariates Controlled

\begin{tabular}{|c|c|c|c|c|c|c|c|}
\hline \multirow{2}{*}{$\begin{array}{l}\text { Dependent } \\
\text { Variable }\end{array}$} & \multirow{2}{*}{$\begin{array}{c}\text { (I) } \\
\text { Nationality }\end{array}$} & (J) & $\begin{array}{c}\text { Mean } \\
\text { Difference }\end{array}$ & Std. & & \multicolumn{2}{|c|}{$\begin{array}{l}\text { 95\% CI for } \\
\text { Difference }\end{array}$} \\
\hline & & Nationality & $(\mathrm{I}-\mathrm{J})$ & Error & Sig. ${ }^{b}$ & LB & UB \\
\hline Total Structural Empowerment & Saudi & Non-Saudi & $-3.35^{*}$ & .85 & $.00^{*}$ & -5.02 & -1.69 \\
\hline PES- Meaning & Saudi & Non-Saudi & -.23 & .16 & .16 & -.54 & .09 \\
\hline PES- Confidence & Saudi & Non-Saudi & -.06 & .13 & .67 & -.31 & .19 \\
\hline PES- Self Determination & Saudi & Non-Saudi & -.09 & .14 & .48 & -.37 & .17 \\
\hline PES- Impact & Saudi & Non-Saudi & -.28 & .18 & .12 & -.63 & .07 \\
\hline Affective Commitment & Saudi & Non-Saudi & -.03 & .24 & .89 & -.49 & .43 \\
\hline Continuance Commitment & Saudi & Non-Saudi & .31 & .25 & .21 & -.18 & .80 \\
\hline Normative Commitment & Saudi & Non-Saudi & -.38 & .22 & .09 & -.81 & .06 \\
\hline
\end{tabular}

Note. Based on estimated marginal means. * The mean difference is significant at the .05 level. $\mathrm{b}=$ Adjustment for multiple comparisons: Bonferroni. $\mathrm{CI}=$ Confidence Interval $(\mathrm{LB}=$ Lower Bound, $\mathrm{UB}=$ Upper Bound).

Based on hospital setting, the results of one-way ANOVA revealed a statistically significant difference among nurses on total structural empowerment and all types of organizational commitment. Based on work unit, the highest statistically significant mean difference was for Pediatrics Unit on the total structural empowerment $(M=$ 21.68, $S D=4.39$ ). For organizational commitment, the greatest statistically significant mean difference was for Pediatrics Unit $(M=5.36, S D=.95)$ on AOC, and for Burn Unit on both COC $(M=5.84, S D=1.11)$ and normative (NOC) $(M=5.39, S D=.52)$. For the length of work shift covariate, compared to other shift lengths, those who worked a 12-hour shift, had the highest statistical significant mean difference on total structural empowerment $(M$ $=22.87, S D=3.98)$, as well as on the forms of organizational commitment: Affective $(M=4.93, S D=1.12)$, Continuance $(M=4.57, S D=.99)$, and Normative $(M=4.75, S D=.88)$ (Table 5). 
Table 5One-Way ANOVA Results Controlling for Confounding Variables

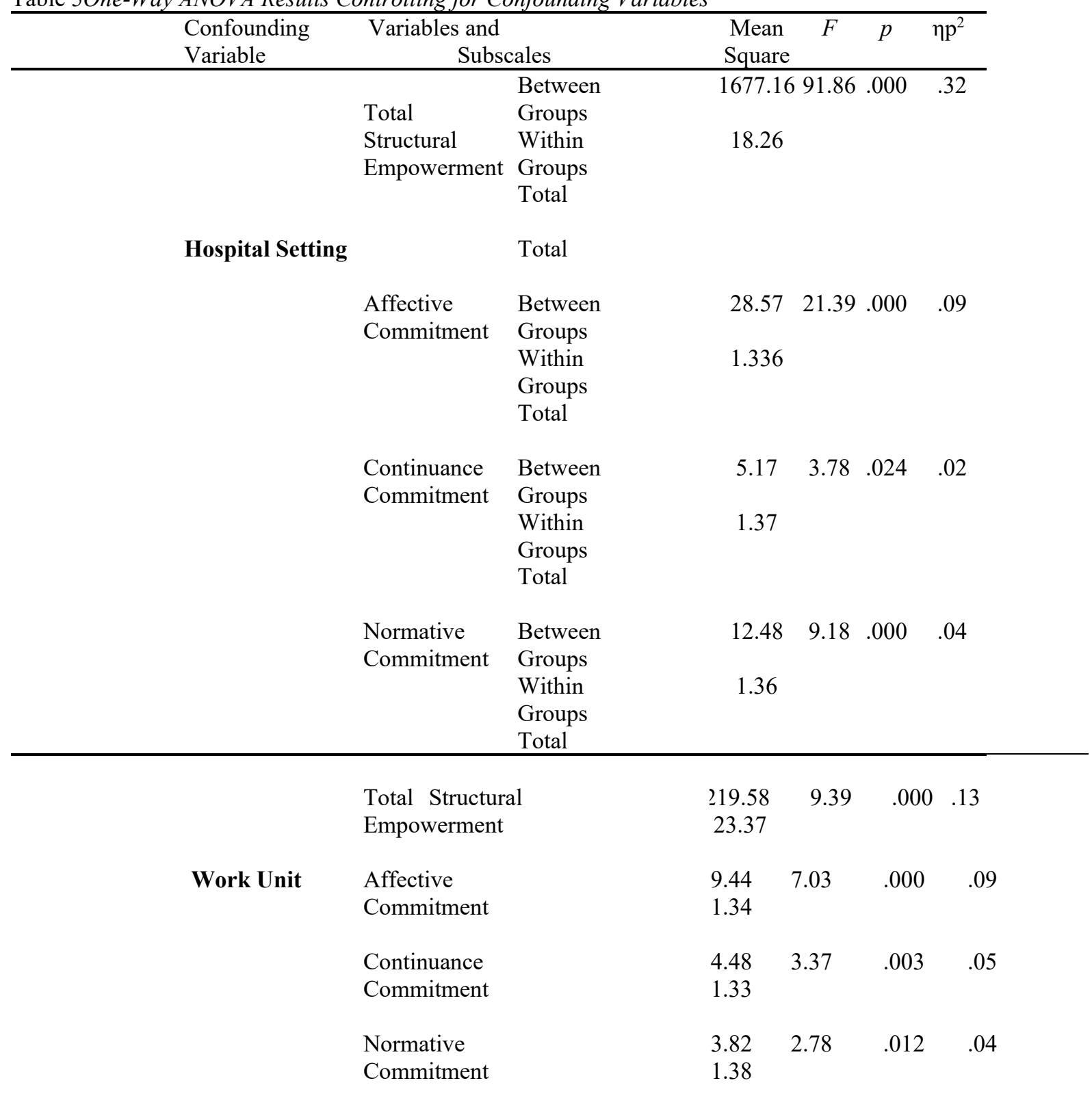

Total Structural

Empowerment

Length of Work Affective

Shift

Commitment

Continuance

Commitment

Normative

Commitment $\begin{array}{llll}944.38 & 0.46 & .000 \quad .28\end{array}$

18.715

$\begin{array}{llll}25.69 & 20.93 & .000 & .14\end{array}$

1.23

0.09

$\begin{array}{llll}1.42 & 0.07 & .933 & 0.00\end{array}$

$\begin{array}{llll}12.41 & 10.82 & 0.000 & 0.08\end{array}$

1.15

\section{DISCUSSIONS}

The majority of the findings of the present study indicated a statistically significant weak positive partial correlation between empowerment and organizational commitment. This correlation reinforces the findings of previous studies on empowerment and organizational commitment conducted in Western countries (Freire \& 
Azevedo, 2015; Yang et al., 2011) and in non-Western countries (Ahmad \& Oranye, 2010; Asiri et al., 2016; Kebriaei et al., 2016).

In comparison with other forms of organizational commitment among nurses in the present study, structural empowerment appeared to have the strongest partial correlation with affective commitment. This provides additional empirical support to the large body of scholarly papers demonstrating the value of affective organizational commitment as having the strongest and most consistent relationship with desirable organizational outcomes (Freire \& Azevedo, 2015; Yang et al., 2014).

As compared to Saudi nurses, non-Saudi nurses felt more structurally empowered and had more affective commitment. Such differences have been highlighted by previous studies, such as those found between nurses from Malaysia and England (Ahmad \& Oranye, 2010), Arab and non-Arab nationalities in Saudi hospital settings (Asiri et al., 2016), and American and Filipino nurses working in the USA (Vacharakiat, 2008). In the present study, these differences may be because of non-Saudi nurses being a minority group coming from or belonging to a high-power distance culture and where having an authoritarian voice might create an impression of managerial incompetence. Kanter (1993) proposed that people from certain ethnic groups, particularly those who are ethnic minorities, can be treated differently in organizations. Ethnic minority groups might feel stressed, socially isolated, unsupported, powerless, and present low or no commitment to the organization. This may explain the finding of affective commitment being more prominent among non-Saudi nurses compared to their Saudi counterparts.

In contrast, the overall low levels of empowerment and commitment reported by Saudi nurses in the present study might be related to the low status of nursing as a profession in Saudi Arabia. The Saudi society has difficulty in accepting nursing as a professional career. The literature indicated that some major reasons for Saudis not to consider nursing as a possible future career or think of leaving the profession included: low social status, facing criticism from family and public due to poor perception of nursing, cultural values and community beliefs (Almalki, 2012). Thus, it is possible that Saudi nurses might have developed an inner sense of feeling disempowered which affects perceptions of empowerment and organizational commitment revealed in this study.

In addition, of the six comparisons found in this study, informal power as an empowerment structure, demonstrated statistically significantly higher correlation with affective commitment among Saudi nurses compared to non-Saudis. Informal power is derived from the ability to build influential relationships with other coworkers (Laschinger et al., 2001). According to Allen and Meyer (1996), affective commitment maintains behavioral direction when there is little expectation of formal rewards. Therefore, it would seem rational that affective commitment motivates those discretionary behaviors among Saudi nurses that do not depend chiefly on formal rewards. Informal power has more to do with the nature of the social exchange and the ability to build influential relationships and effective communication channels across functional groups, including peers, supervisors and subordinates.

It is possible that the confounders (hospital setting, working unit and length of working shift) might have played a role in these relationships. Based on the hospital setting, this study revealed a statistically significant difference among nurses on empowerment and commitment. Yaseen (2017) found that nurses perceived higher structural empowerment at hospitals with Magnet ${ }^{\circledR}$ status compared to non-Magnet ${ }^{\circledR}$ hospitals. Stimpfel et al. (2014) found a positive relationship between Magnet $\AA$ status and higher nursing quality of care, concluding that Magnet ${ }^{\circledR}$ settings attract and retain nurses by enriching the environments with empowerment structures, leading to an optimization of quality nursing care. For the hospital settings included in this study, organizational culture, levels and operationalization of empowerment structures, job-related conditions, and sample characteristics might have affected the relationships among the research variables and might also have attributed to the difference in nurses' perceptions toward empowerment and commitment.

For the work unit as a confounder, in comparison with nurses from other units, the statistically significant higher mean difference empowerment and commitment found among intensive care and burn care nurses in this study may be attributed to the notion that working in such areas is perceived to be challenging and exciting with its high speed and rapid changing environment. In these challenging work units, the continuous individual development, the supportive atmosphere and well-functioning teamwork, having an appropriate mix of jointly developed goals, developing a sense of self-esteem and belief in one's ability to manage work tasks, all in turn, lead to developing an inner sense of strength and power and commitment to the workplace (Miedaner, 2018; Wahlin \& Ek, 2017).

As compared to other work shift categories, the findings of the present study indicated that those who worked a 12-hour shift, had the highest statistically significant mean difference on empowerment and organizational commitment. Comparably, Ahmad and Oranye (2010) found that type of employment (part versus full-time) had a positive association with structural empowerment among English nurses as compared to Malaysian nurses. A possible explanation is that those working less shift hours or those having part-time job opportunities or more stable work shift hours might have more time and opportunity to engage in other activities such as research, social, family and personal affairs. 


\section{LIMITATIONS}

The study implemented a self-report measure; therefore, a common method variance and a risk of response bias cannot be ruled out. The high response rate yielded in this study might not have reflected the actual nurses' response. The contextual influences, including time, location, nursing authority role, nursing shortage and high workload might have influenced response bias. In addition, the cross-sectional and descriptive nature of data limits the generation of strong statements of cause and effect. Furthermore, the use of convenience sampling method from three hospital settings and from one region of Saudi Arabia limits the generalizability to other regions and populations in Saudi Arabia. The data were collected from "bedside" nurses and may not be reflective of all Saudi and non-Saudi nurses. However, the diverse sample in this study might resulted in enhancing the generalizability of the findings to other populations if further studies were carried out in similar contexts.

\section{CONCLUSIONS}

This is possibly the first study of its kind, examining empowerment to study the differences between Saudi and non-Saudi nurses' perceptions in relation to organizational commitment within three healthcare settings in Saudi Arabia. Findings of this study revealed a difference between Saudi and non-Saudi nurses in perceptions of empowerment and organizational commitment. Non-Saudi nurses perceived higher levels of empowerment and commitment compared to Saudi nurses. These findings provided indications for the need of further investigations and interventional plans by the Saudi Ministry of Health to assess the existing working conditions and improve nursing work environment to enhance nurses' empowerment and commitment. Considering the limitations, based on the findings of this study, it would be prudent to replicate this study in multiple or particular units and healthcare settings within Saudi Arabia and the Arab Gulf region to obtain a diverse sample of nurses and test these findings can be generalized to all nurses in the region. Specific areas for future research may address the effect of nurses' empowerment and commitment on organizational outcomes, such as nurses' performance, job satisfaction, retention and intent to leave as well as examining the effect of interventional strategies that might improve empowerment and commitment levels among nurses.

Conflict of Interest

Author declare no funding sources or conflict of interest.

\section{References}

Abumayyaleh, B., Khraisat, O., Hamaideh, S., Ahmed, A., \& Thultheen, I. (2016). Moral distress and turnover intention among critical care nurses in Saudi Arabia. International Journal of Nursing and Health Science, 3(6), 59-64. Retrieved from http://www.openscienceonline.com/journal/ijnhs

Ahmad, N., \& Oranye, N. O. (2010). Empowerment, job satisfaction and organizational commitment: A comparative analysis of nurses working in Malaysia and England. Journal of Nursing Management, 18, 582591. doi:10.1111/j.1365-2834.2010. 01093.x

Alghamdi, M. G., \& Urden, L.D. (2016). Transforming the nursing profession in Saudi Arabia. Journal of Nursing Management, 24, E95-E100. doi:10.1111/jonm.12301

Almalki, J., FitzGerald, G., \& Clark, M. (2012). The relationship between quality of work life and turnover intention of primary health care nurses in Saudi Arabia. BMC Health Services Research, 12, 312-314. doi:10.1186/1472-6963-12-314

Almutairi, D. O. (2015). The mediating effects of organizational commitment on the relationship between transformational leadership style and job performance. International Journal of Business and Management, 11, 231-241. doi:10.5539/ijbm.v11n1p231

Aluwihare, S. D., Gellatly, I., Cummings, G., \& Ogilvie, E. L. (2018). A contextual work-life experiences model to understand nurse commitment and turnover. Journal of Advanced Nursing, 74, 2053-2063. doi: $10.1111 /$ jan. 13718

Al-Yami, M., Galdas, P., \& Watson, R. (2018). Leadership style and organisational commitment among nursing staff in Saudi Arabia. Journal of Nursing Management, 26(5), 531-539. doi:10.1111/jonm.12578

Anderson, V. L., Johnston, A. N., Massey, D., \& Bamford-Wade, A. (2018). Impact of MAGNET hospital designation on nursing culture: an integrative review. Contemporary Nurse, 54(4-5), 483-510. doi:10.1080/10376178.2018.1507677

Asiri, S. A., Rohrer, W.W., Al-Surimi, K., Da'ar, O. O., \& Ahmed, A. (2016). The association of leadership styles and empowerment with nurses' organizational commitment in an acute health care setting: A cross-sectional study. BMC Nursing, 15, 1-10. doi:10.1186/s12912-016-0161-7

Church, C. D., He, Z., \& Yarbrough, S. (2018). Factors influencing organizational commitment and turnover in nurse residents. The Journal of Continuing Education in Nursing, 49(10), 482-488. doi:10.3928/0022012420180918-09

Fragkos, K. C., Makrykosta, P., \& Frangos, C. C. (2020). Structural empowerment is a strong predictor of organizational commitment in nurses: A systematic review and meta-analysis. Journal of Advanced Nursing, 
76(4), 939-962. doi:10.1111/jan.14289

Freire, C. C., \& Azevedo, R. M. (2015). Empowering and trustful leadership: Impact on nurses' commitment. Personnel Review, 44, 702-719. doi:10.1108/PR-01-2014-0021

Gholami, M., Saki, M., \& Hossein Pour, A. H. (2019). Nurses' perception of empowerment and its relationship with organizational commitment and trust in teaching hospitals in Iran. Journal of Nursing Management, 27(5), 1020-1029. doi: 10.1111/jonm.12766

Kanter R. M. (1977). Men and women of the corporation ( $1^{\text {st }}$ ed.). New York, NY: Basic Books.

Kanter, R. M. (1993). Men and women of the corporation ( $2^{\text {nd }}$ ed.). New York, NY: Basic Books.

Kebriaei, A., Keykhaei, A., Zahiri, M., \& Moosavi, G. (2016). The mediating role of organizational commitment on the relationship between psychological empowerment and turnover intention. International Journal of Humanities and Cultural Studies (IJHCS), 3(3), 112-125. Retrieved from https:/ijhcs.com/index.php/ijhcs/article/view/2554

Laschinger, H. K. S., Finegan, J., Shamian, J., \& Wilk, P. (2004). A longitudinal analysis of the impact of workplace empowerment on work satisfaction. Journal of Organizational Behavior, 4, 527-545. doi:10.1002/job.256

Miedaner, F., Kuntz, L., Enke, C., Roth, B., \& Nitzsche, A. (2018). Exploring the differential impact of individual and organizational factors on organizational commitment of physicians and nurses. BMC health services research, 18, 180. doi:10.1186/s12913-018-2977-1

Laschinger, H. S., Finegan, J., Shamian, J., \& Wilk, P. (2001). Impact of structural and psychological empowerment on job strain in nursing work settings: Expanding Kanter's model. The Journal of Nursing Administration, 31, 260-272. doi:10.1097/00005110-200105000-00006

Laschinger, H., \& Havens, D. (1996). Staff nurse work empowerment and perceived control over nursing practice: Conditions for work effectiveness. Journal of Nursing Administration, 26(9), 27-35. Retrieved from https://journals.lww.com/jonajournal/toc/1996/09000

Laschinger, H., Finegan, J., \& Wilk, P. (2009). Context matters: The impact of unit leadership and empowerment on nurses' organizational commitment. Journal of Nursing Administration, 39, 228-235. doi:10.1097/NNA.0b013e3181a23d2b

Lee, Y. W., Dai, Y. T., Chang, M. Y., Chang, Y. C., Yao, K. G., \& Liu, M. C. (2017). Quality of work life, nurses' intention to leave the profession, and nurses leaving the profession: A one-year prospective survey. Journal of Nursing Scholarship, 49, 438-444. doi:10.1111/jnu.12301

Meng, L., Liu, Y., Liu, H., Hu, Y., Yang, J., \& Liu, J. (2015). Relationships among structural empowerment, psychological empowerment, intent to stay and burnout in nursing field in mainland China based on a crosssectional questionnaire research. International Journal of Nursing Practice, 21, 303-312. doi: 10.1111/ijn.12279

Meyer, J. P., Allen, N. J., \& Smith, C. A. (1993). Commitment to organizations and occupations: Extension and test of a three-component conceptualization. Journal of Applied Psychology, 78, 538-551. doi:10.1037/00219010.78.4.538

Rodwell, J., McWilliams, J., \& Gulyas, A. (2017). The impact of characteristics of nurses' relationships with their supervisor, engagement and trust, on performance behaviours and intent to quit. Journal of Advanced Nursing, 73, 190-200. doi:10.1111/jan.13102

Salem, O. A., Baddar, F., \& AL-Mugatti, H. M. (2016). Relationship between nurses' job satisfaction and organizational commitment. Journal of Nursing and Health Science, 5, 49-55. doi:10.9790/1959-05114955

Stimpfel, A. W., Rosen, J. E., \& McHugh, M. D. (2014). Understanding the role of the professional practice environment on quality of care in Magnet ${ }^{\circledR}$ and non-Magnet hospitals. The Journal of nursing administration, 44, 10. doi: 10.1097/NNA.0000000000000015

Vacharakiat, M. (2008). The relationships of empowerment, job satisfaction, and organizational commitment among Filipino and American registered nurses working in the U.S.A (Doctoral dissertation). Retrieved from ProQuest Dissertations and Theses. (AAT: 3340548).

Wåhlin, I., Ek, A.-C., \& Idvall, E. (2017). Patient empowerment in intensive care: An interview study. Intensive \& Critical Care Nursing, 22, 370-377. doi:10.1016/j.iccn.2006.05.003

Wong, C. A., \& Laschinger, H. K. S. (2013). Authentic leadership, performance, and job satisfaction: The mediating role of empowerment. Journal of Advanced Nursing, 69, 947-959. doi:10.1111/j.1365-2648.2012. 06089.x

Yang, J., Liu, Y., Chen, Y., \& Pan, X. (2014). The effect of structural empowerment and organizational commitment on Chinese nurses' job satisfaction. Applied Nursing Research, 27, 186-191. doi:10.1016/j.apnr.2013.12.001

Yaseen.M. (2017). Organizational, nurse, and patient empowerment at a magnet and non-magnet hospital (Doctoral dissertation). Retrieved from ProQuest Dissertations and Theses. (AAT: 10608634). 